No. 2107

ESTIMATING THE EFFECTS OF TAX REFORM IN DIFFERENTIATED PRODUCT OLIGOPOLISTIC MARKETS

Chaim Fershtman, Neil Gandal and Sarit Markovich

INDUSTRIAL ORGANIZATION

AND PUBLIC POLICY

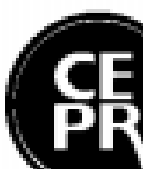

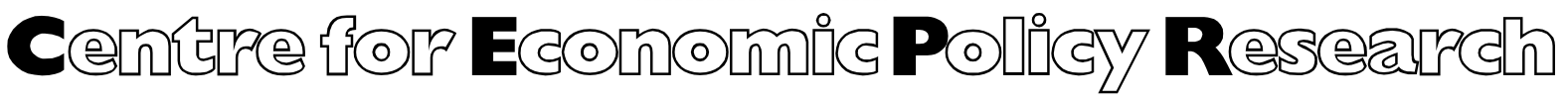




\title{
ESTIMATING THE EFFECTS OF TAX REFORM IN DIFFERENTIATED PRODUCT OLIGOPOLISTIC MARKETS
}

\author{
Chaim Fershtman, Neil Gandal and Sarit Markovich
}

\author{
Discussion Paper No. 2107 \\ March 1999 \\ Centre for Economic Policy Research \\ 90-98 Goswell Rd \\ London EC1V 7RR \\ Tel: (44 171) 8782900 \\ Fax: (44 171) 8782999 \\ Email: cepr@cepr.org
}

\begin{abstract}
This Discussion Paper is issued under the auspices of the Centre's research programme in Industrial Organization and Public Policy. Any opinions expressed here are those of the author(s) and not those of the Centre for Economic Policy Research. Research disseminated by CEPR may include views on policy, but the Centre itself takes no institutional policy positions.
\end{abstract}

The Centre for Economic Policy Research was established in 1983 as a private educational charity, to promote independent analysis and public discussion of open economies and the relations among them. It is pluralist and non-partisan, bringing economic research to bear on the analysis of medium- and long-run policy questions. Institutional (core) finance for the Centre has been provided through major grants from the Economic and Social Research Council, under which an ESRC Resource Centre operates within CEPR; the Esmée Fairbairn Charitable Trust; and the Bank of England. These organizations do not give prior review to the Centre's publications, nor do they necessarily endorse the views expressed therein.

These Discussion Papers often represent preliminary or incomplete work, circulated to encourage discussion and comment. Citation and use of such a paper should take account of its provisional character.

Copyright: Chaim Fershtman, Neil Gandal and Sarit Markovich 
CEPR Discussion Paper No. 2107

March 1999

\section{ABSTRACT}

\section{Estimating the Effects of Tax Reform in Differentiated Product} Oligopolistic Markets

The incidence of taxation has been extensively discussed in the public finance literature, but mainly within a competitive market setting or within a homogenous good (Cournot type) oligopoly. In a differentiated product oligopoly the effect of taxation can be more complex as the rate of taxation may affect not only the prices, but also the profile and quality of products that are sold in the market. In this paper, we examine the effects of changing tax regimes in a differentiated product oligopoly. In order to illustrate our approach we employ data from one such market: the automobile market in Israel

JEL Classification: H2, L8

Keywords: taxation, differentiated product oligopoly

Chaim Fershtman

Department of Economics

Tel Aviv University

Tel Aviv 69978

ISRAEL

Tel: (972 3) 6407167

Fax: (972 3) 6409908

Email: fersht@econ.tau.ac.il
Neil Gandal

Department of Public Policy

Tel Aviv University

Tel Aviv 69978

ISRAEL

Tel: (972 3) 6406742

Fax: (972 3) 6407382

Email: gandal@econ.tau.ac.il

Sarit Markovich

Department of Economics

University of Chicago

1126 East 59th Street

Chicago

IL 60637

USA

Tel: (1 773) 7028254

Fax: (1 773) 7028490

Email:smarkovi@midway.uchicago.edu

Submitted 8 February 1999 


\section{NON-TECHNICAL SUMMARY}

In an oligopoly, in which products are differentiated both horizontally and vertically, the effect of taxation may be complex since the tax regime may affect not only prices, but also the profile and quality of the products that each firm sells. In this paper, we examine these issues in an oligopolistic market with horizontally and vertically differentiated products in which firms (may) sell multiple brands. The paper investigates the effect of changes in the taxation regime on equilibrium prices, tax incidence, the size and composition of the market, consumer surplus, government tax revenues and firm profits. While we apply our framework using the automobile market in Israel, the type of analysis we employ is applicable to other differentiated product oligopolies.

In order to illustrate the complex effect of taxation in a differentiated good oligopoly, we consider the automobile industry. Let us assume that in the relevant market, there are several firms that sell automobiles. Each of the firms sells different models. The models are vertically differentiated in that they differ in size, quality, features etc. At any given point in time these firms compete in prices. In determining the price for a specific model, each firm must take into account competition from other firms as well as the effect of the price of a particular model on the sales of its other models. Now assume that a tax is imposed. This will change the market equilibrium and will affect not just the prices of cars but also the equilibrium distribution of cars that each firm sells. For example, it is possible that a uniform increase in the tax rate, while reducing overall sales in the market and overall sales of a particular firm, may increase sales of particular model. Such an effect will occur if, for example, as a result of the tax increase there is a shift in demand to smaller cars.

In our analysis, we employ recent advances in estimating discrete-choice models of product differentiation. These techniques, developed by Berry (1994) and Berry, Levinsohn, and Pakes (1995), enable structural estimation of both the demand and oligopoly pricing aspects that characterize differentiated products. The model of oligopolistic competition that we employ is based on Berry (1994). We use the model and data on prices, quantities, and characteristics of the Israeli automobile market in 1994 and 1995 (the latest years for which the data are available) to estimate the demand and cost parameters for this market.

Given the estimated parameters, we analyse the effects of different tax regimes by simulating the oligopolistic market equilibrium under such regimes. The importance of the simulation is that it allows firms to adjust prices, as well as allowing for changes in quantity demanded. 
An ad valorem tax regime is currently in place in Israel. We examine the effect of changes in the percentage tax rate, as well as the effect of two alternative tax regimes: (i) a regime that consists of a per unit tax and (ii) a tax based on engine size, as is common in several European countries (see Verboven, 1996). By comparing these regimes with the uniform percentage tax regime, we illustrate the product differentiation and market power effects that arise from changes in tax regimes.

We show that a change in the tax regime from an ad valorem tax to a per unit tax regime leads to significant reductions in the sales of small automobiles and significant increases in the sales of large automobiles. The change in composition is due to vertical product differentiation among the models. This demand effect is somewhat mitigated by market power. Firms take advantage of the increase in demand for larger cars (from the change in tax regime) by lowering prices by less than the reduction in taxes.

Finally, we quantify the benefits of using a set-up with heterogeneous demand and oligopolistic market structure in estimating the effect of government taxation rather than the standard set-up of a competitive market. Here we examine the change in government revenue and consumer surplus derived from a change in tax policy under the assumption that the market is competitive and that the products are homogeneous. We show that in the case of a tax cut, the competitive model overestimates the reduction in government tax revenue and overestimates the gain in consumer surplus and these overestimates are fairly significant.

The main contribution of this paper is the framework it adopts. Our approach could be used by regulators to predict the effect of different tax policies, not only on tax revenues and the number of cars that are sold in the market, but also on the distribution of the type of automobiles that are sold. Hence, different tax regimes can be evaluated and compared for their effect on the average engine size (which determines the consumption of fuel), the percentage of automobiles that offer safety features (such as airbags and ABS brakes), as well as the level of imports. 


\section{Introduction:}

The incidence of taxation and the design of an optimal tax system have been extensively discussed in the Public Finance literature; most of the work on this subject has been conducted within the framework of a competitive market or within the framework of a homogenous good oligopoly characterized by Cournot competition. Auerbach (1985) provides a good theoretical survey on commodity taxation in competitive markets. Katz and Rosen (1985), Myles (1987), and Stern (1987) examine commodity taxation issues such as tax design, optimal taxes and tax incidence in oligopolies in which firms compete on quantities and sell homogeneous products. In this paper we examine, both theoretically and empirically, the issues of tax reform in a very relevant market: oligopoly markets in which firms sell differentiated products.

In an oligopoly, in which products are differentiated both horizontally and vertically, the effect of taxation may be complex since the tax regime may affect not only prices, but also the profile and quality of the products that each firm sells. In this paper, we examine these issues in an oligopolistic market with horizontally and vertically differentiated products in which firms (may) sell multiple brands. In particular, the paper investigates the effect of changes in the taxation regime on equilibrium prices, tax incidence, the size and composition of the market, consumer surplus, government tax revenues, and firm profits. While we apply our framework using the automobile market in Israel, the type of analysis we employ is applicable to other differentiated product oligopolies.

In order to illustrate the complex effect of taxation on a differentiated good oligopoly, consider the automobile industry. Let us assume that in the relevant market, 
there are several firms that sell automobiles. Each of the firms sells different models. The models are vertically differentiated in that they differ in size, quality, features etc. At any given point in time these firms compete in prices. In determining the price for a specific model, each firm must take into account competition from other firms as well as the effect of the price of a particular model on the sales of its other models. Now assume that a tax is imposed. This will change the market equilibrium and will affect not just the prices of cars but also the equilibrium distribution of cars that each firm sells. For example, it is possible, that a uniform increase in the tax rate, while reducing overall sales in the market and overall sales of a particular firm, may increase sales of particular model. Such an effect will occur if, for example, as a result of the tax increase there is a shift in demand to smaller cars.

In our analysis, we employ recent advances in estimating discrete-choice models of product differentiation. These techniques, developed by Berry (1994) and Berry, Levinsohn, and Pakes (1995), enable structural estimation of both the demand and oligopoly pricing aspects that characterize differentiated products. The model of oligopolistic competition that we employ is based on Berry (1994) and is similar to the one used by Verboven (1996) and the one used in our previous work (Fershtman and Gandal (1998)). ${ }^{1}$ We use the model and data on prices, quantities, and characteristics of the Israeli automobile market in 1994 and 1995 (the latest years for which the data are available) to estimate the demand and cost parameters for this market.

Given the estimated parameters, we analyze the effects of different tax regimes by simulating the oligopolistic market equilibrium under such regimes. The importance of 
the simulation is that it allows firms to adjust prices, as well as allowing for changes in quantity demanded. ${ }^{2}$

An ad valorem tax regime is currently in place in Israel. In the paper, we examine the effect of changes in the percentage tax rate, as well as the effect of two alternative tax regimes: (i) a regime that consists of a per unit tax and (ii) a tax based on engine size, as is common in several European countries (see Verboven, 1996). By comparing these regimes with the uniform percentage tax regime, we illustrate the product differentiation and market power effects that arise from changes in tax regimes.

We show that a change in the tax regime from an ad valorem tax to a per unit tax regime leads to significant reductions in the sales of small automobiles and significant increases in the sales of large automobiles. The change in composition is due to vertical product differentiation among the models. This demand effect is somewhat mitigated by market power. Firms take advantage of the increase in demand for larger cars (from the change in tax regime) by lowering prices by less than the reduction in taxes.

We are aware of two purely theoretical papers that examine the effect of taxation in differentiated product oligopolies. Gruenspecht (1988) considers the effect of export subsidies in an oligopoly in which firms sell horizontally differentiated products and compete on prices. In his model, price reductions do not bring new customers into the market; they only lead to market diversion from other competitors. Our setting explicitly allows for both effects and we measure them.

\footnotetext{
${ }^{1}$ In Fershtman and Gandal (1998), we examined the effect of the Arab economic boycott on the Israeli automobile industry and estimated the peace dividend (in this industry) associated with the elimination of the boycott.

${ }^{2}$ There are very few simulations that allow for both sides of the market to adjust. Most other simulations in this literature keep prices fixed.
} 
Cremer and Thisse (1994) examine the effect of commodity taxation in a setting in which firms sell vertically differentiated products and compete on prices. They show that an increase in taxes reduces the quality of the products that oligopolists will provide. Although we assume that the brands offered are fixed in the short run, our empirical results show that consumers purchase more subcompact and compact vehicles (lower quality products relative to large and midsize cars) when taxes increase. Thus the change in the tax rate leads to a demand shift. In the long run, the demand effect resulting from the tax change would likely encourage firms to reduce the number of 'premium' models they sell and offer more models in the subcompact and compact classes. In this sense, our results are in the spirit of Cremer and Thisse (1994); increases in taxes would lead to a shift in the distribution of sales to smaller and lower quality cars.

Empirical work in the literature has almost exclusively been conducted under the assumption that the relevant industry is competitive. Kenkel (1996) examines the optimal rate of taxation on alcohol. In his setting, he assumes that there is a single "alcoholic" product that is priced at marginal cost. He acknowledges that the "alcoholic beverage industry is probably better described as oligopolistic, but the implications for tax incidence are unclear" (Kenkel (1996) p. 300). To the best of our knowledge, Barnett, Keeler, and $\mathrm{Hu}$ (1995) is the only paper that empirically employs an oligopoly model to examine the effect of taxation. Using a Cournot model with homogeneous products to model competition among manufacturers in the cigarette industry, they examine the incidence of cigarette taxes. Using the estimated parameters, they simulate the effect of changes in the rate of cigarette taxation. Given that there is not a great deal of vertical 
differentiation among the popular cigarette brands, the homogeneous Cournot model is probably a reasonable model to use in their setting.

In the automobile market in Israel, the price among the available models ranges in 1995 from $\$ 14,833$ for a Fiat Uno (a 1.1 Liter engine with a standard transmission and no air-conditioning) to $\$ 64,987$ for a Volvo 960 (a 3.0 liter engine, air-conditioning, automatic transmission, airbags, ABS brakes, and other premium features). Clearly, we cannot model competition in this industry by employing a Cournot model with homogeneous products. We need a model that not only captures total sales, but also the composition of the (differentiated) products sold in the market.

\section{The Oligopolistic Model}

We model the automobile industry as an oligopolistic market with $\mathrm{N}$ multiproduct firms. Short run competition among the firms is through prices. Market demand is determined by aggregating a discrete choice model of consumer behavior.

\subsection{Demand}

Following Berry (1994), we use a random utility model, in which the utility of product $\mathrm{j}$ to consumer $\mathrm{i}, u_{i j}$, is:

$$
u_{i j}=x_{j} \beta-o p_{j}+\xi_{j}+\varepsilon_{i j}
$$

where $x_{j}$ is a vector of observed product characteristics (such as engine size) and $p_{j}$ is the price of automobile j. $\alpha$ and $\beta$ are parameters to be estimated. The last two terms of (1) are error terms: $\xi_{\mathrm{j}}$ is the average value of product $\mathrm{j}$ 's unobserved characteristics (and is 
the same for all consumers) and $\varepsilon_{i j}$ represents the distribution of consumer preferences around this mean. The term $\varepsilon_{i j}$ introduces heterogeneity and its distribution determines the substitution patterns among products. Under the assumption that the $\varepsilon_{i j}$ are identically and independently distributed across consumers and products with the extreme value (Weibull) distribution function, the probability of choosing product $\mathrm{j}$ (the market share of product $\mathbf{j}$ ) is given by:

$s_{j}=\frac{e^{\delta_{j}}}{\left(\sum_{k} e^{\delta_{k}}\right)}$,

where

$\delta_{j} \equiv x_{j} \beta-\alpha p_{j}+\xi_{j}$,

is the mean utility level from product $\mathrm{j}$. It is well known that this "logit" distribution yields unreasonable substitution patterns among products; ${ }^{3}$ it is commonly used because it yields a closed form solution for the market share of each product.

In order to overcome the unreasonable substitution patterns, similar to other authors, we employ the "nested" multinomial logit model. Goldberg (1995) and Verboven (1996) also employ variants of the nested logit model in their studies of the automobile industry.

Although, the nested logit model also has its limitations, it yields a more reasonable pattern of substitution among products than the logit model. Unlike the logit, 
the nested logit results in a higher degree of substitution among cars that belong to the same group than among cars from different groups.

As Berry (1994) notes, the nested logit is appropriate when the substitution effects among products depend primarily on predetermined classes of products. This assumption seems reasonable in the case of automobiles; indeed industry groups employ a standard classification system that puts each car in one of the following groups: subcompact, compact, midsize, large, and luxury/sport, according to its characteristics.

In the nested logit model, the products are grouped into $\mathrm{G}+1$ sets, where the outside good, $\mathrm{j}=0$, is assumed to be the only member of group 0 . The difference between the logit and the nested logit is that there is an additional variable, denoted $\zeta$, which is common to all products in group $\mathrm{g}$ and has a distribution that depends on $\sigma, 0 \leq \sigma<1$. In the case of the nested logit model, the utility of consumer $i$ from product $j$ is $u_{i j}=\delta_{j}+\zeta_{i j}+(1-\sigma) \varepsilon_{i j}$, where $\delta_{j} \equiv x_{j} \beta-\alpha p_{j}+\xi_{j}$ is again the mean utility level and $\zeta+(1-\sigma) \mathcal{E}$ also has an extreme value (Weibull) distribution. In this case, the probability of choosing product $\mathrm{j}$ in group $\mathrm{g}$ is:

$$
s_{j}=\frac{e^{\delta_{j} /(1-\sigma)}}{D_{g}^{\sigma}\left(\sum_{g} D_{g}^{1-\sigma}\right)}
$$

where $D_{g}=\sum_{\left[j \in G_{g}\right]} e^{\delta_{j} /(1-\sigma)}, \mathrm{G}_{\mathrm{g}}$ denotes the set of automobiles of type $\mathrm{g}$, and $0 \leq \sigma<1$ is an additional parameter to be estimated; it measures the degree of substitution among the products in the classes or groups. If $\sigma=0$, the cross elasticities among products do not

\footnotetext{
${ }^{3}$ For more on general extreme value (GEV) models, see McFadden (1978).
} 
depend on the classification; in this case, the simple multinomial logit model (Eq. (1)) is appropriate. When $\sigma>0$, there is a higher degree of substitution among cars that belong to the same group than among cars from different groups. If $\sigma$ approaches one, the cross elasticity between any two cars that belong to different groups approaches zero.

We use the nested logit model to estimate the equilibrium in the Israeli automobile market. As shown in Berry (1994), Eq. (4) can be inverted to yield the following equation:

$\ln \left(s_{j} / s_{0}\right)=x_{j} \beta-\alpha p_{j}+\sigma \ln \left(\bar{s}_{j / g}\right)+\xi_{j}$,

where $\bar{s}_{j / g}$ is the share of product $\mathrm{j}$ in group g, and $s_{0}$ is the proportion of consumers that choose not to purchase a new car, that is, the proportion of consumers that choose the outside good. Following the literature, we assume that the size of the potential market (denoted $\mathrm{M}$ ) is known; $s_{0}$ is then the difference between the size of the potential market and the actual market. Since the price and the group share are endogenous, we can obtain consistent estimates of $\alpha, \beta$ and $\sigma$ from an instrumental variable regression.

\subsection{Multiproduct Oligopoly Pricing}

We assume that the marginal cost of producing each product is independent of the output levels and linear in a vector of cost characteristics. The assumption of constant marginal cost is typically employed in the relevant literature. Moreover, since the Israeli automobile market is small compared to the world market, the assumption of constant marginal cost is quite realistic in this case. The marginal cost of good $\mathrm{j}$ is: 
$m c_{j}=\omega_{j} \gamma+v_{j}$

where $\omega_{j}$ is a vector of observable characteristics, $v_{j}$ is an unobserved cost characteristic and $\gamma$ is a vector of unknown parameters to be estimated.

The operating profits of a multiproduct firm $f$ selling $\mathrm{F}$ different types of automobiles are:

$\pi_{f}=\sum_{k=1}^{F}\left(p_{k} /(1+t)-m c_{k}\right) q_{k}$,

where $p_{k}$ is the retail price of product $\mathrm{k}, q_{k}$ is the corresponding quantity sold, $\mathrm{t}$ is the tax rate, and $m c_{k}$ is the marginal cost of producing automobile $\mathrm{k}$.

We assume that firms compete through prices and that they only take into account the cross elasticities among their products within a group. It can be shown (with a lot of tedious algebra - see Verboven (1996)) - that the first order condition (pricing equation) for product $\mathrm{j}$ is:

$\frac{p_{j}}{1+t}=\omega_{j} \gamma+\frac{(1-\sigma)}{\alpha(1+t)\left[1-\sigma \sum_{k \in f_{g}} q_{k} / Q_{g}-(1-\sigma) \sum_{k \in f_{g}} q_{k} / M\right]}+v_{j}$

where $f_{g}$ represents the set of products that firm $f$ is selling in group $\mathrm{g}, \mathrm{Q}_{\mathrm{g}}$ is the total number of sales in group g, and $M=\sum_{i=0}^{N} q_{i}$. The last term on the right hand side is 
endogenous, suggesting that instrumental variables are also needed in order to estimate the pricing equation.

\section{Estimation}

The model to be estimated consists of the demand and the pricing equations (Eqs. (5) and (8) respectively). We estimate this two equation system using the general method of moments (GMM). We chose to employ GMM estimation for the following reasons: (i) the unobserved demand characteristics, $\xi_{j}$, and the unobserved cost characteristics, $v_{j}$, might be correlated; (ii) $\alpha$ and $\sigma$ appear in both equations; (iii) the equations are not linear in $\alpha$ and $\sigma$. Additionally, other methods require structure on the correlation between the error terms of the demand and oligopoly pricing equation. GMM estimation does not require additional assumptions on the error term. Finally, GMM, which is an iterative procedure (like maximum likelihood), is preferable to 3SLS, which essentially involves a single iteration.

\subsection{Instruments}

We need to specify instruments for both the demand and the pricing equations. The endogenous terms for which we need instruments are product shares within a group $\left(\bar{s}_{j / g} \equiv q_{j} / Q_{g}\right)$, firm shares within a group, $\left(\sum_{k \in G_{g}} q_{k} / Q_{g}\right)$, and prices. We use the characteristics of other cars and cost shifters as instruments.

The number of other products in a group and the sum of the characteristics of other products in a group are negatively correlated with within-group shares, and 
therefore can be used as instruments for this variable. Now consider firm shares within a group. This variable is positively correlated with the number of other products the firm sells in the group and with the sum of the characteristics of the other cars it sells in the group. Further, firm shares within a group are negatively correlated with the number of products sold by competitors in the group, and with the sum of characteristics of products sold by competitors in the group. Finally, we consider instruments for price. The pricing equation suggests that an increase in the number of other automobiles that a firm sells within the group will increase the price. An important additional instrument for price is the change in the exchange rate between 1994 and $1995 .{ }^{4}$

\subsection{Data}

In the Israeli market the luxury/sport class is extremely small (due to the relatively high rate of taxation); hence we employ the classes: subcompact, compact, midsize and large. Approximately 113,000 automobiles were sold in both 1994 and 1995. More than 170 different products were available in each year. ${ }^{5}$ Restricting the sample to brands that had more than 80 sales, left 213 brands: 101 models in 1994 and 112 models in 1995.

In Israel, all import licenses are exclusive, and the exclusive dealer sets prices. We used the Levi price book for price data, where prices are in New Israeli Shekels. ${ }^{6}$ The Levi price book, which is the most popular price book in Israel, includes the car features; ${ }^{7}$ hence for each price observation, we know what additional features were available ${ }^{8}$.

\footnotetext{
${ }^{4}$ Of course, all of the instruments are valid for all of the endogenous variables; we discuss the instruments in this manner so that we can provide the economic intuition behind the choice of instruments.

${ }^{5}$ Models with different engine size are different products.

${ }^{6}$ The average exchange rate in both 1994 and 1995 was 3.00 New Israeli Shekels $=\$ 1.00$.

${ }^{7}$ In the Israeli market, many premium features (like dual airbags, automatic transmission, automatic braking system (ABS) etc.) are included as standard equipment or not available.

${ }^{8}$ In the case in which options are available, we took the model with the fewest options.
} 
The retail price includes taxes of 144 percent on automobiles subject to custom duties, and 128 percent on automobiles not subject to custom duties. Total taxes are composed of the following three components: (i) a 95 percent luxury tax on private automobiles, (ii) a 17 percent value added tax and (iii) a 7 percent customs tax; the taxes are cumulative. All private automobiles are subject to the luxury and value added tax. Automobiles that are produced and imported from the United States, Canada, and European Countries are exempt from custom duties because of free trade agreements. Automobiles from Japan and South Korea are not currently exempt from custom duties.

Our data includes the variable ENGINE, which is the engine size in liters, and the dummy variables SUBCOMPACT, COMPACT, MIDSIZE and LARGE; these variables take on the value one if the automobile belongs to one of these classes. The dummy variables AIRCONDITION and AUTOMATIC take on the value one if the model has air conditioning or automatic transmission (respectively). AIRBRAKE takes on the value two if the model has both airbags and ABS brakes system, one if the model has only one of these features, and zero if it has none of the features.

The dummy variable YEAR95 takes on the value one if the model was sold in 1995 and zero if the model was sold in 1994. EXCHANGE takes on the value zero if the model was sold in 1994 and equals the percentage change (from 1994 to 1995) in the exchange rate of the manufacturer's country currency versus the New Israeli Shekel, if the model was sold in 1995. The dummy variables JAPAN95, KOREA95, USA95, ITALY95 GERMANY95 and FRANCE95 take on the value one for 1995 automobiles that are produced in the relevant country. (These countries account for 85 percent of the 
automobiles sold in Israel in 1994-1995.) Descriptive statistics for these variables are shown in tables $\mathrm{A}$ and $\mathrm{B}$ in the appendix.

\subsection{GMM Estimation}

In the estimation we include the variables ENGINE, AIRCONDITION, AUTOMATIC, AIRBRAKE both in the observable demand characteristics, $x_{j}$, and the observable cost characteristics, $\omega_{j}$. Additionally, the cost characteristics vector includes the variables EXCHANGE, YEAR95, JAPAN95, KOREA95, USA95, ITALY95 GERMANY95 and FRANCE95; the country dummy variables are included solely to examine the change in the marginal cost of production for each country from 1994 to 1995. (Country dummies for 1994 would have no meaning since EXCHANGE takes on the value zero if the model is sold in 1994.) The estimated coefficients associated with the other variables are virtually unchanged if we exclude the country dummy variables. The demand characteristic vector includes a dummy variable for compact automobiles (denoted COMPACT); this variable is included because this class of vehicles is especially popular.

The instruments we employ are the sum of the engine sizes of the other products in the group, the sum of the engine sizes of the other products that a firm sells in the group, the number of other products in the group, the number of other products that a firm sells in the group, and the change in the exchange rate between 1994 and 1995. The results of the GMM estimation are shown table 1.

The estimates of the marginal cost of air conditioning and automatic transmission are in line with the option prices that are listed separately in the Levi price book (Recall 
that the prices are in New Israeli Shekels.) In addition the model predicts that the marginal cost of producing French, German and Japanese automobiles increased significantly in 1995 relative to the typical 1994 automobile; ${ }^{9}$ these increases were primarily due to significant appreciation of the French, German, and Japanese currencies against the New Israeli Shekel during the 1994-1995 period.

The estimated elasticities of demand also seem quite plausible: the average (sales weighted) elasticity of demand is -4.80 ; the breakdown is -3.53 for the subcompact class, -4.70 for the compact class, -5.62 for the midsize class, and -9.15 for the large class.

The model predicts that similar to the U.S., there is some market power in the Israeli automobile market: the average (sales weighted) price-cost margin is 10 percent. This is slightly lower than the price-cost margins obtained by BLP (1995) for the U.S. automobile industry.

In an earlier version of the paper, we showed that with the exception of the constant parameter in the demand equation, the parameter estimates are virtually unchanged when we significantly increase the size of the potential market from $M=400,000$ to $M=600,000$. As expected, the parameter estimate of the constant is significantly smaller when $M=600,000$. A larger potential market $(M=600,000)$ means that more consumers chose the outside good than one of the available automobiles. This reduces the mean utility of all inside goods relative to the outside good.

\subsection{Consumer Surplus}

\footnotetext{
${ }^{9}$ For French cars, the increase was 3009 NIS. (The calculation is as follows: $-2,293+640 * 11-1,648$, since the French Franc appreciated by 11\% relative to the NIS from 1994 to 1995.) The increases in the marginal costs of producing Japanese and German cars were 2,285 NIS and 6,075 NIS respectively.
} 
Consumer surplus is calculated by noting that the equations in (4) are a system of probabilistic demand functions for individual i. This system exhibits all of the properties of deterministic demand functions. Therefore in the case of the nested logit model, consumer surplus per person (up to a constant) is given by: ${ }^{10}$

$\mathrm{W}=\log \left(\sum_{g} D_{g}^{1-\sigma}\right) / \alpha$

Since we are interested in changes in consumer surplus associated with changes taxation, the constant is not essential.

\subsection{Simulation of the Market}

Given the parameters estimated in the previous section, in sections 4 and 5 we simulate the equilibrium of the oligopolistic market equilibrium under different tax regimes. The importance of the simulation is that it allows firms to adjust prices, as well as allowing for changes in quantity demanded. Technically, each simulation involves solving 224 nonlinear equations, i.e., 112 demand equations (equation (5)) and 112 pricing equations (equation (8)) for each model without the error terms. ${ }^{11}$

In the following section, we analyze the effects of changes in the ad valorem tax rate. In section 5, we examine two alternative tax regimes.

\section{The Effect of Changes in the Ad Valorem Tax Rate.}

\footnotetext{
${ }^{10}$ See McFadden (1978) for details.

${ }^{11}$ This system was solved using software programs that we wrote; the software programs employed the GAUSS nonlinear simultaneous-equations subroutine.
} 
We first examine the effect of the elimination of customs duties; these duties are only in effect for Japanese and Korean cars. This symmetry insures that our results in sections 4.1 and 4.2 below are not due to asymmetric taxation rates for automobiles that are identical except for country of origin. ${ }^{12}$

We hence simulate the market under the assumption that all cars are subject to a $128 \%$ tax rate (the current tax rate without custom duties). ${ }^{13}$ Our market simulation indicates that eliminating custom duties on the Japanese and Korean cars increases sales by $2.3 \%$, while government revenues from taxes decrease by $1.8 \%$. The distribution among the four classes shifts from subcompact cars to compact cars, while the shares of the midsize and large classes stay almost the same. (This is because Japanese and Korean automobiles make up a very large portion of the compact class. See table B in the appendix.)

The elimination of the custom tax leads to an increase in the share of Japanese and Korean automobiles in each class while the share of European and American (E\&US) decreases. Custom elimination implies a 6.6\% reduction in the tax burden (for Japanese and Korean vehicles), where we define the tax burden to be the percentage change in prices such that the dealer price $\mathrm{p} /(1+\mathrm{t})$ is unchanged before and after the tax change. The simulation shows that Japanese and Korean firms would lower prices in the 4.1\%-5.8\% range, following the elimination of custom duties. This implies that part of the tax

\footnotetext{
${ }^{12}$ Since Israel is now a signatory to the GATT, it suggests that the custom duties will be eliminated in the near future.

${ }^{13}$ Because of the custom duties, the current tax on Japanese and Korean cars is $144 \%$.
} 
reduction is passed onto consumers. The consumers' share of the tax reduction is higher in the larger classes. Total consumer surplus increases by $\$ 46.9$ Million or 1.2 percent. ${ }^{14}$

Since the profits are all owned by foreign firms, the reduction in aggregate excess burden from the elimination of custom duties is the gain in consumer surplus less the decline in tax revenues or \$21.9 Million (\$46.9 Million less 25.0 Million).

Even though it does not affect excess burden, the elimination of custom duties has a significant effect on the profits of the different foreign firms. The profits of American and European manufacturers fall by $4-10$ percent, while the profits of the Japanese and Korean firms rise by anywhere from 20-33 percent. Honda has the largest increase in profits (33\%); this is because their models are in the midsize and large classes. Thus despite the fact that the distribution of sales among classes does not change significantly, the distribution of sales (and profits) within classes changes significantly. Table 2 summarizes the effects of eliminating customs duties:

\subsection{A Change in the Ad Valorem Tax Rate from $128 \%$ to $100 \%$.}

Our basis for comparative statics in this section is the $128 \%$ uniform tax rate. Here we examine a tax reform that results in a decrease in the tax rate to $100 \%$. Keeping the same tax regime enables us to examine the robustness of results to changes in parameters of the model.

Our simulations shows that the reduction in the uniform tax rate to $100 \%$ increases the market size by $10.4 \%$ relative to a $128 \%$ uniform tax; there is a rightward

\footnotetext{
${ }^{14}$ We use the equilibrium market size before the elimination of custom duties, although an argument could be made to use the predicted market size from the simulation following the elimination of the duties. We are consistent throughout the paper: we use the equilibrium market size before the relevant change in tax policy to compute the change in consumer surplus.
} 
shift towards larger automobiles, since these cars are now relatively less expensive. See table 3.

The economic reason for substitution towards larger cars when taxes fall from $128 \%$ to $100 \%$ is because the absolute tax decreases are larger in these classes. While the size of the "shift" is affected by the assumption that utility is linear in prices, qualitatively similar results would obtain even if utility were not linear in prices.

The reduction in the tax rate reduces the tax burden by 12.3 percent. (Recall that the tax burden is the percentage change in prices such that the dealer price $p /(1+t)$ is unchanged before and after the tax change.) Table 3 shows that sales weighted prices fall by 9.4 percent; hence, consumers receive a significant share of the benefit from the reduction in the luxury tax. The percentage decline in prices is greater for larger cars.

Table 3 also shows the "total elasticity of automobile demand," which measures the relative demand for automobiles and the outside good. The total elasticity of demand is calculated by dividing the percentage change in overall sales $(+10.4 \%)$ by the sales weighted percentage change in prices $(-9.4 \%)$. Hence the total elasticity of automobile demand is approximately -1.1 .

The size of the market increases by $11,169(+10.4 \%)$ and consumer surplus increases by 238.4 Million ( $+8.7 \%$ ) following the decrease in the luxury tax. Government revenues from taxes fall by $\$ 120.0$ Million (-8.7\%), while firms' profits increase by $\$ 60.3$ Million (25.5\%). Table 4 summarizes these results.

\subsubsection{Robustness of Results: Changes in the Size of the Potential Market}


The estimates of tax incidence and overall elasticity of automobile demand are robust to changes in the size of the potential market. When the size of the potential market is 600,000 rather than 400,000 (i.e., 50 percent higher), the total elasticity of automobile demand is approximately -1.3 . The slightly more elastic total elasticity of automobile demand is because the size of the (potential) market is larger when $M=600,000$. The only significant difference is in the absolute level of sales. At a tax rate of 100 percent and a potential market size of 400,000, predicted sales in the market are 119,034; at the same tax rate, when $M=600,000$, predicted sales are 114,262 . This must be the case, because estimating the model with a larger potential market (but no other changes, i.e., tax rate stays the same) means that more consumers chose the outside good. As discussed above, this reduces the mean utility of all inside goods (automobiles) relative to the mean utility of the outside good and hence the simulation predicts that less automobiles will be purchased.

Thus, the size of the potential market is just a scaling factor and doesn't significantly affect tax incidence or the elasticity of demand between the inside and the outside goods. This is important, since, the potential market size is typically something that must be assumed. We continue the analysis with $M=400,000$.

\subsubsection{Robustness of the Results to Changes in the Degree of Substitution Between}

\section{Classes of Automobiles ( $\sigma)$.}

When $\sigma$ is relatively small, equation (8) shows that the mark-up over marginal cost is primarily a function of the firm's share in the total market, while when $\sigma$ is relatively large, the mark-up over marginal cost is primarily a function of the firm's share 
within the relevant class of cars. When $\sigma$ approaches 1 , the price cost margin goes to zero, i.e., the market becomes very competitive; hence for larger values of $\sigma$, we would expect firms to bear a larger portion of the tax burden.

We simulated the market for $\sigma=.63$ and $\sigma=.77$, i.e., one standard deviation below and one standard deviation above the estimated value $(\sigma=.70)$. On average, a reduction in the tax rate from $128 \%$ to $100 \%$, leads to a price fall of 9.0 percent for the case when $\sigma=.63$ vs. 9.9 percent for the case when $\sigma=.77$ (Recall that in the case when $\sigma=.70$, the estimated value, prices fall on average by 9.4 percent). The simulations with $\sigma=.63$ and $\sigma=.77$ show that the overall elasticity of demand for automobiles remains unchanged (1.1) as $\sigma$ changes.

\subsection{Precision of Results}

In order to get some sense of the precision of the effect of the changes in taxation policy, we performed the following "bootstrap" experiment for consumer surplus. It was assumed that the estimated coefficients from Table 1 were the true means and the estimated standard deviations were the true standard deviations of the unknown parameters. Further, we assumed that each of these parameters was normally distributed. Using (9), we then computed 5000 estimates of the change in consumer surplus. Figure 1 shows that the estimated standard deviation of the aggregate gain in consumer surplus from the reduction in the tax rate from $128 \%$ to $100 \%$ is approximately $\$ 24.9$ Million. 


\subsection{Benefits From Estimating Oligopolistic Model with Differentiated Products ${ }^{15}$}

What are the benefits of using a setup with heterogeneous demand and oligopolistic market structure in estimating the effect of government taxation rather than the standard setup of a competitive market? To study this issue, we examine the change in government revenue and consumer surplus derived from a change in tax policy under the assumption that market is competitive and that the products are homogeneous. Specifically, we make the assumption that the percentage change in sales from the reduction in the tax rate from 128 percent to 100 percent is exactly as we measured using the oligopoly model. Then the change in government tax revenue (i.e., the change in price*quantity*tax rate (pqt)) is simply pq $\mathrm{dt}+\mathrm{pt} \mathrm{dq}$. The first term is given by total revenue in the market (at the 128 percent tax rate equilibrium) multiplied by the change in the tax rate, (100-128)/228; this yields $-\$ 301.4$ Million. The second term is total tax revenue at the 128 percent tax rate equilibrium multiplied by the change in sales $(10.4 \%)$; this yields \$143.3 Million. Hence the "standard" model estimates that government revenue falls by $\$ 158.1$ million. Since the gain in consumer surplus is simply -pq dt, the standard model estimates that reducing the tax rate from $128 \%$ to $100 \%$ results in an increase of \$301.4 Million in consumer surplus.

Table 4 shows that consumer surplus under the oligopoly model increases by \$238.4 Million when the tax rate is reduced from $128 \%$ to $100 \%$. The difference between the two consumer surplus measures is $\$ 63$ Million, which is approximately the estimated value of the increase in firm profits ( $\$ 60.3$ Million from Table 4) when the tax rate decreases. Hence the oligopoly profit effect from the increase in demand (associated

\footnotetext{
${ }^{15}$ We are grateful to Roger Gordon for suggesting that we conduct the analysis in this section and for providing the framework for the analysis.
} 
with the decrease in the tax rate) is fairly significant -- approximately 25.3 percent of the increase in consumer surplus. This profit effect is not captured in the standard model.

Table 4 also shows that tax revenues fall by $\$ 120$ Million, rather than $\$ 158.1$ Million as predicted by the standard model. This difference is due to the increase in demand for and sales of large cars (see table 3). Hence the standard model overestimates the reduction in government tax revenue and overestimates the gain in consumer surplus and these overestimates are fairly significant.

\section{Alternative Tax Regimes: Per Car Tax \& Tax Based on Engine Size}

In this section, we examine the effect of alternative taxation regimes. In particular, we consider (i) a per unit tax and (ii) a tax based on engine size. The effects of product differentiation and market power can be illustrated by comparing these taxation regimes to the (100 percent) uniform tax rate.

Note that both of these taxes are "additive", rather than multiplicative. Hence, the first order condition (7) becomes

$\pi_{f}=\sum_{k=1}^{F}\left(p_{k}-m c_{k}-T_{k}\right) q_{k}$

and the pricing equation (8) becomes

$$
p_{j}=T_{j}+\omega_{j}+\frac{(1-\sigma)}{\alpha\left[1-\sigma \sum_{k \in f_{g}} q_{k} / Q_{g}-(1-\sigma) \sum_{k \in f_{g}} q_{k} / M\right]}+v_{j}
$$


where "T" is the amount of the tax.

\subsection{Per Unit Taxes}

We first consider a per unit tax; such a tax is "regressive" in the sense that the effective tax rate is higher on smaller vehicles. We examine a shift from a $100 \%$ uniform tax rate to a constant absolute tax of $\$ 10,500$ per vehicle (the average tax per automobile in the case of a 100 percent uniform tax). ${ }^{16}$

The effect of vertical product differentiation is illustrated by the change in the tax regime. This demand shift significantly affects the composition of the market: sales of subcompacts decline by 23.9 percent and sales of compacts decline by 13.4 percent relative to sales under the 100 percent uniform tax rate. On the other hand, sales of midsize automobiles rise slightly (by 1.8 percent) and sales of large automobiles increase significantly (by 38.6 percent).

Of course, market power also affects sales. Firms take advantage of the increase in demand for larger cars. In the case of large cars, the change in regime leads to a per vehicle tax reduction of 36.2 percent. Prices on the other hand, only decline by 10.7 percent. The significant increase in demand for large cars provides firms with an incentive to raise prices. This offsets much of the percentage decline in taxes and, to some extent, mitigates the demand effect.

In the case of midsize cars, the final price to consumers actually increases by 6.3 percent, despite the 8.6 percent decline in taxes on midsize cars. Although prices

\footnotetext{
${ }^{16}$ When making regime changes, authorities are often concerned that tax revenue remains unchanged. It is straightforward to conduct this exercise. We chose to examine the per unit tax that leaves average tax per automobile equal to the previous regime because it illustrates the effects of market power and product differentiation clearly.
} 
increase, sales of midsize cars actually increase overall by 1.8 percent. This is because the demand effect (associated with the change in tax regime) more than offsets the higher prices.

For subcompact cars, the demand effect works in the opposite direction. Hence, overall prices rise by "only" 34.8 percent, less than the percentage increase in taxes (37.6 percent) on these vehicles. (See table 5.)

The change in tax regimes leads to a 7.8 percent decline in total sales from approximately 119,000 to slightly less than 110,000 . Total consumer spending rises by 8.8 percent. This is again due to the demand effect associated with the change in tax regime. Consumers switch to larger cars, which have become relatively less expensive. Given the above discussion, it is not surprising that firm profits increase significantly (by 83.6 percent). This is intuitive because profits per automobile are greater for larger cars and many more large automobiles are sold. (See table 6.)

\subsection{Tax on Engine Size}

Here, we examine a change in the tax regime from a $100 \%$ uniform tax to a tax on engine size, with the tax approximately equal to $\$ 6600$ times the size of the engine (in liters). ${ }^{17}$ This results in a tax of $\$ 10,500$ (the average tax per vehicle in the case of a 100 percent uniform tax) on the average size automobile (1.6 liter engine) in the market. This tax is still regressive relative to the uniform tax rate, but much less so than the very regressive constant tax. Hence the changes in prices and automobile sales by class are

\footnotetext{
${ }^{17}$ Differential tax rates based on engine size are employed in Europe. For example, both Belgium and Italy charge higher tax rates for automobiles with large engine sizes. (See Verboven 1996).
} 
less dramatic than in the case of changing from a uniform tax rate to a constant tax per automobile.

Prices of all classes of automobiles rise, with the percentage increase in prices decreasing in the size of the car. Sales also decrease monotonically by class; sales of subcompacts fall by 13.3 percent, while sales of large cars fall just by 0.8 percent. Table 5 summarizes these changes, which again are due to a combination of product differentiation, market power, and the relative changes in taxes per automobile.

\section{Concluding Remarks}

While the paper examines the effect of different tax regimes on the Israeli automobile market, the main contribution of this paper is the framework it adopts. As we have shown, in oligopolistic industries, taxation affects the profile of goods that are sold as well as relative prices in a way that depends on the elasticity of demand of all products and the degree of competition in the market.

Our approach could be used by regulators to predict the effect of different tax policies, not only on tax revenues and the number of cars that are sold in the market, but also on the distribution of the type of automobiles that are sold. Hence, different tax regimes can be evaluated and compared for their effect on the average engine size (which determines the consumption of fuel), the percentage of automobiles that offer safety features (such as Airbags and ABS brakes), as well as the level of imports. 


\section{Acknowledgments}

We are especially grateful to Roger Gordon and an anonymous referee for suggestions that significantly improved the manuscript. We also thank seminar participants at Haifa University, Tel Aviv University, the University of Texas, and the 1997 EARIE Conference in Louvain for helpful comments. We thank the Sapir Center for Development for Financial Support.

\section{References}

Auerbach, A., 1985. The theory of Excess Burden and Optimal Taxation. In A. Auerbach and M. Feldstein, (Eds.), Handbook of Public Economics, Vol. 1 North-Holland, Amsterdam.

Barnett, P., Keeler, T., and T. Hu, 1995. Oligopoly Structure and the Incidence of Cigarette Excise Taxes. Journal of Public Economics 57, 457-470.

Berry, S, 1994. Estimating Discrete-Choice Models of Product Differentiation. RAND Journal of Economics 25, 334-347.

Berry, S., J. Levinsohn, and A. Pakes, 1995. Automobile Prices in Market Equilibrium. Econometrica 63, 841-890.

Cremer, H. and J. F. Thisse, 1994. Commodity Taxation in Differentiated Oligopoly. International Economic Review 35, 613-633.

Fershtman, C., and N. Gandal, 1998. The Effect of the Arab Boycott on Israel: The Automobile Market. RAND Journal of Economics 29, 193-214.

Goldberg, P., 1995. Product Differentiation and Oligopoly in International Markets: The Case of the U.S. Automobile Industry. Econometrica 63, 891-952.

Gruenspecht, H., 1988. Export Subsidies for Differentiated Products. Journal of International Economics 24, 331-344.

Katz, M., and H. Rosen, 1985. Tax Analysis in an Oligopoly Model. Public Finance Quarterly 13, 3-19.

Kenkel, D., 1996. New Estimates of the Optimal Tax on Alcohol. Economic Inquiry 34, 296-319. 
McFadden, D., 1978. Modeling the Choice of Residential Location. In A. Karlquist et al. (Eds.), Spacial Interaction Theory and Planning Models. North Holland, Amsterdam.

Myles, G., 1987. Tax Design in the Presence of Imperfect Competition: An Example. Journal of Public Economics 34, 36-378.

Stern, N., 1987. The Effects of Taxation, Price Control and Government Contracts in Oligopoly and Monopolistic Competition. Journal of Public Economics 32, 133-158.

Verboven, F., 1996. International Price Discrimination in the European Car Market. RAND Journal of Economics 27, 240-268. 


\begin{tabular}{|l|l|l|l|l|}
\hline \multicolumn{4}{|l|}{ Both Equations } & \multicolumn{2}{l|}{} \\
\hline Parameter & Coefficient & Standard Error & & \\
\hline$\alpha$ & $2.1 \times 10^{-5}$ & $8.6 \times 10^{-6}$ & & \\
\hline$\sigma$ & 0.70 & 0.07 & & \\
\hline & \multicolumn{4}{|l|}{} \\
\hline & Demand Equation & \multicolumn{3}{l|}{} \\
\hline Variable & Coefficient & Standard Error & Coefficient & Standard Error \\
\hline CONSTANT & -2.56 & 0.34 & -5849 & 3449 \\
\hline ENGINE & 0.13 & 0.15 & 14517 & 1663 \\
\hline AIRBRAKE & 0.15 & 0.09 & 7467 & 1045 \\
\hline AUTOMATIC & 0.15 & 0.08 & 3463 & 1349 \\
\hline AIRCONDITIO & 0.19 & 0.09 & 2203 & 1081 \\
\hline COMPACT & 0.72 & 0.09 & & \\
\hline EXCHANGE & & & 640 & 765 \\
\hline YEAR95 & & & -2293 & 3452 \\
\hline GERMANY95 & & & 47 & 8340 \\
\hline JAPAN95 & & & -1182 & 4806 \\
\hline FRANCE95 & & & -1648 & 6199 \\
\hline USA95 & & & 1893 & 4426 \\
\hline KOREA95 & & & 3204 & 5700 \\
\hline ITALY95 & & & 3423 & 4140 \\
\hline GMM OBJ & 16.61 & & & \\
\hline
\end{tabular}

Table 1: GMM Results (M=400,000) 


\begin{tabular}{|l|l|l|}
\hline $\begin{array}{l}\text { Changes following the } \\
\text { elimination of custom duties }\end{array}$ & actual change & \% change \\
\hline Size of the Market & $+2,408$ & +2.3 \\
\hline Total Spending (Millions \$) & +4.6 & +0.19 \\
\hline Tax Revenues (Millions \$) & -25.0 & -1.8 \\
\hline Consumer Surplus (Million \$) & +46.9 & +1.2 \\
\hline Total Firms' Profits (Millions \$) & +11.5 & +5.1 \\
\hline
\end{tabular}

Table 2: Changes Following the Elimination of Custom Duties 


\begin{tabular}{|l|l|l|l|l|l|}
\hline Fall in tax rate from 128\% to $100 \%$ Overall \\
\hline & Subcompact & Compact & Mid size & Large & Ove \\
\hline $\begin{array}{l}\text { \% change in } \\
\text { price }\end{array}$ & -8.6 & -9.4 & -9.9 & -10.6 & -9.4 \\
\hline $\begin{array}{l}\text { \% change in } \\
\text { sales }\end{array}$ & 5.5 & 9.4 & 13.2 & 23.2 & 10.4 \\
\hline
\end{tabular}

Table 3. (\% Change in Prices \& Sales by Class from Decline in Tax Rate) 


\begin{tabular}{|l|l|l|}
\hline $\begin{array}{l}\text { Changes following decrease in the } \\
\text { luxury tax from } 128 \% \text { to } 100 \%\end{array}$ & $\begin{array}{l}\text { Actual } \\
\text { changes }\end{array}$ & change \\
\hline Size of the Market & $+11,169$ & +10.4 \\
\hline Total Spending (Millions \$) & +61.8 & +2.5 \\
\hline Tax Revenues (Millions \$) & -120.0 & -8.7 \\
\hline Consumer Surplus (Million \$) & +238.4 & +8.7 \\
\hline Total Firms' Profits (Millions \$) & +60.3 & +25.5 \\
\hline
\end{tabular}

Table 4: (Global Changes From Decline in Tax Rate from 128\% to 100\%) 


\begin{tabular}{|c|c|c|c|c|}
\hline & Subcompact & Compact & Mid size & Large \\
\hline \multicolumn{5}{|c|}{ Tax on Engine Size: $\$ 6600 \times$ engine size (liters) } \\
\hline $\begin{array}{l}\text { \%change in } \\
\text { price }\end{array}$ & 21.2 & 16.3 & 11.5 & 4.8 \\
\hline $\begin{array}{l}\text { \%change in } \\
\text { sales }\end{array}$ & -13.3 & -12.8 & -7.3 & -0.8 \\
\hline $\begin{array}{l}\text { \% change in } \\
\text { taxes }\end{array}$ & +10.1 & +7.3 & +1.6 & -0.6 \\
\hline \multicolumn{5}{|c|}{ Per Unit Tax of $\$ 10,500$ per vehic le } \\
\hline $\begin{array}{l}\text { \%change in } \\
\text { price }\end{array}$ & 34.8 & 16.5 & 6.3 & -10.7 \\
\hline $\begin{array}{l}\text { \%change in } \\
\text { sales }\end{array}$ & -23.9 & -13.4 & +1.8 & +38.6 \\
\hline $\begin{array}{l}\text { \% change in } \\
\text { taxes }\end{array}$ & +37.6 & +7.8 & -8.6 & -36.2 \\
\hline
\end{tabular}

Table 5. (\% Change in Prices \& Sales by Class from Changes in Tax Regimes) 


\begin{tabular}{|l|l|l|l|l|}
\hline & \multicolumn{2}{|l|}{$\begin{array}{l}\text { Per Unit Tax } \\
\$ 10,500 \text { per vehicle }\end{array}$} & \multicolumn{2}{l|}{$\begin{array}{l}\text { Tax on Engine Size } \\
\$ 6600 \text { x engine size (liters) }\end{array}$} \\
\hline $\begin{array}{l}\text { Changes relative to } \\
\text { Uniform tax of 100\% }\end{array}$ & $\begin{array}{l}\text { Actual } \\
\text { changes }\end{array}$ & $\%$ change & $\begin{array}{l}\text { Actual } \\
\text { changes }\end{array}$ & change \\
\hline Size of the Market & $-9,227$ & -7.8 & $-12,675$ & -10.6 \\
\hline Total Spending (Millions \$) & +222.6 & +8.8 & +96.2 & +3.8 \\
\hline Tax Revenues (Millions \$) & -98.1 & -7.8 & -96.5 & -7.7 \\
\hline Consumer Surplus (Million \$) & -224.5 & -6.8 & -307.5 & -9.3 \\
\hline Total Firms' Profits (Millions \$) & +247.9 & +83.6 & +232 & +78.1 \\
\hline Note: In both cases, the comparison is made with the ba se ca se: a 100\% uniform tax rate. \\
\hline
\end{tabular}

Table 6. (Global Changes Associated With Different Taxation Regimes 
Appendix

\begin{tabular}{r|c|c|c||} 
& \multicolumn{3}{|l||}{} \\
\hline Variable & Mean & Maximum & Minimum \\
\hline & \multicolumn{3}{|l||}{} \\
\hline PRICE & 68481 & 194962 & 29999 \\
\hline QUANTITY & 1044 & 11447 & 80 \\
\hline EIRCONDITION & 1.63 & 3.8 & 1.00 \\
\hline AUTOMATIC & 0.21 & 1.00 & 0.00 \\
\hline AIRBAGS & 0.12 & 1.00 & 0.00 \\
\hline ABS BRAKES & 0.07 & 1.00 & 0.00 \\
\hline SMALL & 0.25 & 1.00 & 0.00 \\
\hline COMPACT & 0.52 & 1.00 & 0.00 \\
\hline MEDIUM & 0.16 & 1.00 & 0.00 \\
\hline LARGE & 0.07 & 1.00 & 0.00 \\
\hline JAPAN & 0.34 & 1.00 & 0.00 \\
\hline KOREA & 0.16 & 1.00 & 0.00 \\
\hline FRANCE & 0.13 & 1.00 & 0.00 \\
\hline ITALY & 0.12 & 1.00 & 0.00 \\
\hline USA & 0.07 & 1.00 & 0.00 \\
\hline EXRMANY & 0.04 & 1.00 & 0.00 \\
\hline YEAR95 & 0.50 & 1.00 & 0.00 \\
\hline & & & -3
\end{tabular}

Table 1: Descriptive Statistics 


\begin{tabular}{r||c|c|c|c|c||}
\hline \multicolumn{1}{|c||}{} & \multicolumn{1}{c||}{} \\
\hline \hline 1994 Total Sales & 25026 & 58075 & 19004 & 9087 & 111192 \\
\hline 1994 Models & 19 & 37 & 20 & 25 & 101 \\
\hline 1994 J \& K Sales & 3733 & 36773 & 13031 & 1579 & 55116 \\
\hline 1994 J \& K Models & 5 & 11 & 10 & 6 & 32 \\
\hline 1994 "Boycott" Sales & 1240 & 28848 & 12206 & 1579 & 43873 \\
\hline 1994 "Boycott" Models & 1 & 8 & 8 & 6 & 23 \\
\hline & \multicolumn{5}{|c||}{} \\
\hline 1995 Total Sales & 31155 & 57129 & 15381 & 7614 & 111279 \\
\hline 1995 Models & 33 & 33 & 27 & 19 & 112 \\
\hline 1995 J \& K Sales & 2241 & 47763 & 4744 & 891 & 55639 \\
\hline 1995 J \& K Models & 6 & 16 & 12 & 2 & 36 \\
\hline 1995 "Boycott" Models & 2 & 13 & 11 & 2 & 28 \\
\hline
\end{tabular}

Table 2: Automobile Sales by Group (J\&K, Japan and Korea). 
Figure 1. Aggregate Gain in Consumer Surplus (in \$ Million) from Reduction in the tax Rate from $128 \%$ to $100 \%$.

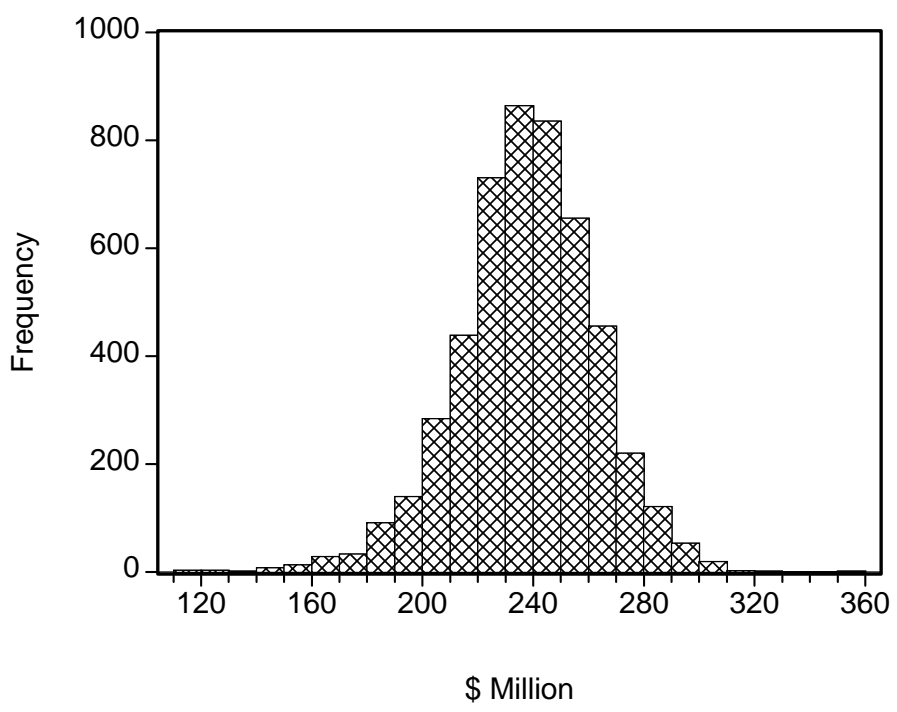

Series: Aggregate Gain in Consumer Surplus $\mathrm{N}=5000$

Mean 237.7395

Median 238.3828

Maximum $\quad 359.5700$

Minimum $\quad 111.3214$

Std. Dev. 24.90927

Skewness $\quad-0.343505$

Kurtosis $\quad 4.087427$

Jarque-Bera $\quad 344.4072$

Probability $\quad 0.000000$ 